POLLACK PERIODICA

An International Journal for Engineering and Information Sciences

DOI: $10.1556 / 606.2017 .12 .1 .7$

Vol. 12, No. 1, pp. 81-92 (2017)

www.akademiai.com

\title{
FINITE-ELEMENT SIMULATION OF THE COLD STAMPING PROCESS OF SPHERICAL VESSELS
}

\author{
${ }^{1,2}$ Ivan M. BEREZIN, ${ }^{1}$ Alexandre A. PETUNIN, ${ }^{2}$ Dimtrij I. KRYUCHKOV \\ ${ }^{3}$ George L. KOVÁCS \\ ${ }^{1}$ Institute of Mechanics and Machine Building \\ Ural Federal University, named after the first President of Russia B.N.Yeltsin \\ Russia, 620002, Ekaterinburg, Mira str, 19, e-mail: a.a.petunin@urfu.ru \\ ${ }^{2}$ Institute of Engineering Science, Ural Branch of the Russian Academy of Sciences \\ Russia, 620049, Ekaterinburg, Komsomolskaya str, 34, e-mail: berezin@imach.uran.ru \\ ${ }^{3}$ Computer and Automation Research Institute, Hungarian Academy of Sciences \\ H-1111 Budapest, Kende u, 13-17, Hungary, e-mail: kovacs.gyorgy@sztaki.hu
}

Received 25 September 2016; accepted 5 February 2017

\begin{abstract}
A specific process of manufacturing of vessel shell tabs, namely the method of cold stamping is studied in this paper. Recommendations are proposed to gain the proper technology of manufacturing spherical vessels with a volume above 600 cubic meters with regard to labor saving of tabs stamping on hydraulic press. The necessity of having proper technology of stamping is motivated by the large quantity of manual operations, having a direct influence on the conversion costs of a spherical vessel as a whole. The importance of this research is connected with the necessity of multiple shape control of tabs being manufactured during stamping and time-consuming point-by-point shaping-up. The reduction of material costs is supported by using finite-element simulation. Problems are solved with specific modules of the computer aided engineering-system ABAQUS. The results of some finite-element simulations are described. The analysis of stress-strain state at each step of the application of loads is performed.
\end{abstract}

Keywords: Spherical vessel, Stamping, Sheet metal, Shell nesting, Finite-element simulation

\section{Introduction}

The main goal of this work is to examine manufacturing processes used to make spheroidal/spherical vessels with a volume from 600 to 6,600 cubic meters. The other goal is to save labor costs by modifying (optimizing if possible) the manufacturing technology using given machines at a given experimental site. The examination of general application possibilities of the results for different other machines and workshops is a problem of future research. Process optimization and Computer Aided Design (CAD) systems, as [1] states are necessary to decrease the amount of manual operations, which are rather expensive. 
Spherical vessels are used to store pressurized and liquefied gases. The first highpressure storage vessels were built in the 1910s in the USA, and in the 1920s in Europe in connection with the construction of pipelines. The first storages represented the completely riveted cylindrical pressure vessels with spherical bottoms. Their geometric volume was 50-100 cubic-meter $\left(\mathrm{m}^{3}\right)$, and the working pressure was 0.2-0.6 MPa. Later, the centralized construction of larger vessels with a geometric volume of 1,000-5,000 $\mathrm{m}^{3}$ began. However, installing this type of vessels contributed to increased fire hazard. Moreover, too great wall thickness was needed for the riveted cylindrical vessels of proper diameter. Spherical vessels (Fig. 1) became more rational tanks for storing liquids and gases under pressure, because the geometric form of a sphere accepts the best burst pressure with less wall thickness and surface area of a shell comparing to cylindrical vessels of the same capacity. Spherical shapes require less area for their placement, they need less communications and additional equipment.

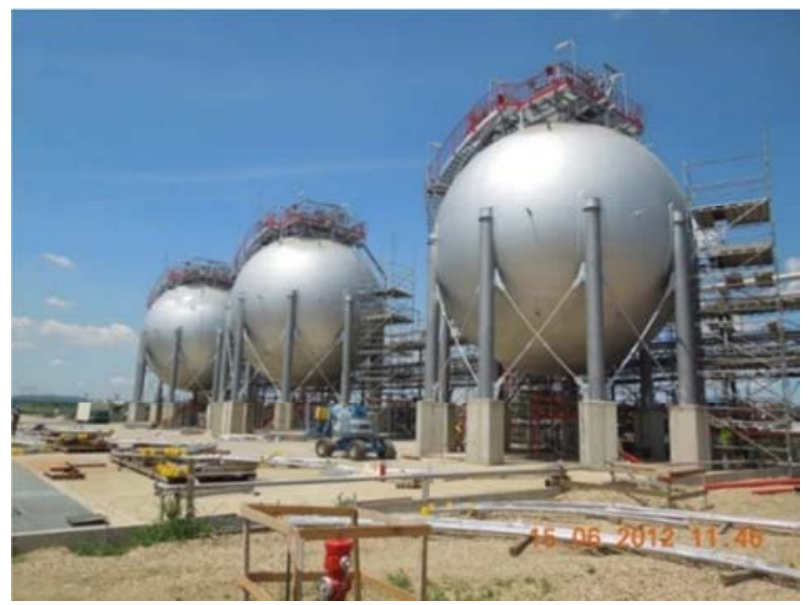

Fig. 1. Spherical vessels at the oil refinery in Pancevo, Serbia [2]

Different nesting arrangements of spherical vessel shells are known [3], as options:

1. platonic solids nesting or otherwise the 'football' type nesting,

2. meridional nesting;

3. equatorial-meridional nesting;

4. combined nesting, and others.

Fig. 2 shows the nesting pattern for the housings of spherical vessels with a volume of $600 \mathrm{~m}^{3}$. As it is seen, the consolidation of the elements allows reducing the length of the mounting seams. For nesting, according to the options 1, 2, and 3, the spherical shape is provided by stamping. The petals according to option 4 are obtained by cold rolling. The equatorial-meridional nesting ( 3 Fig. $2 c$ ) and the meridional nesting (4 Fig. 2d) are the most often used types for vessels of bigger diameter, with a volume of over 600 cubic meters. The shell here consists of long bi-curved tabs and two end caps, top and bottom. 
There are various methods of manufacturing of petals of the large-diameter vessel shells [4]. Basically, petals are produced by hot or cold stamping, and cold rolling. As addition the hydraulic blowing manufacturing methods are known, too [5]-[6]. The shell manufacturing by hydraulic blowing involves the formation of the vessel shell mold using the excessive hydraulic pressure on the welded plane polyhedron.

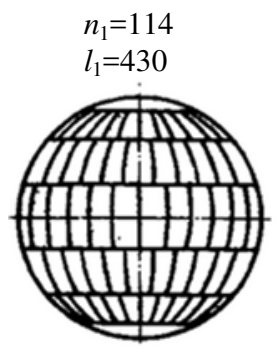

a)

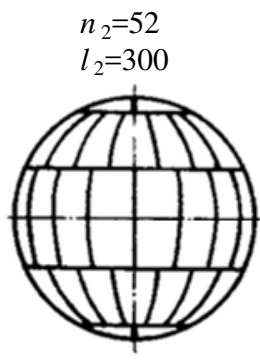

b)

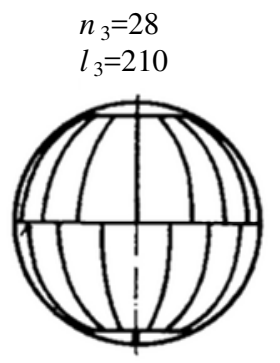

c)

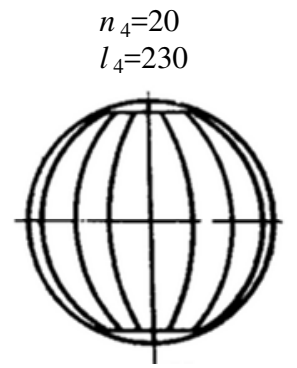

d)

Fig. 2. Types of spherical vessel shells nesting $n$ is the number of petals, $l$ is the length of welding joints (m)

Some advantages of this technology compared with other methods are the following: There is no need of the press and associated press dies; and it is easy to control the dimensional accuracy of each formed component in both stages of preforming the segment and fabricating the preform.

There is a reconfigurable discrete die forming, (or multi-point forming [7]-[8]) used for manufacturing airplane sheets and locomotive parts. However, it is not possible for forming curved shell petals from high-strength steels of high thickness. It is just to mention that applying high temperatures and mechanical reinforcement (see [9] and [10]) may have further positive effects.

The stamping is the most widely used method in the practice of mass production of long sheet bars with large thickness (the width of a sheet is $2-2.5 \mathrm{~m}$, length is $6-10 \mathrm{~m}$, metal thickness is above $30 \mathrm{~mm}$ ). In the manufacturing process by sequential local plastic deformations, the sheets are shaped into the part of a spherical shell in accordance with the desired radius of curvature. During the shaping, the curvature of petals is measured by a metallic flat pattern, and after the shaping completion the measurements are made using spatial patterns. A curvature deviation of $5 \mathrm{~mm}$ by $1.5 \mathrm{~m}$ of pattern length is allowed. The special features are inherent to the welding production in the construction of spherical vessels, namely: small-scale and in some cases individual structures building, a large extent of field joints with a substantial mass of weld metal, the joints must be welded in different spatial positions. The welding of field joints especially that of the steel plates of high strength, must meet a number of additional specific requirements:

1. The formation of weld joints in all positions with equal or close welding performance; 
2. The creation of high technological strength in the root of the weld joint through the implementation of a welded joint in a single pass;

3. The creation of the base metal automatic heating conditions to eliminate preheating and prevent the occurrence of martensitic structure in the heat affected area;

4. The formation of a welded joint with a minimum mass of weld metal.

All the above requirements to the assembly-welding operations cannot be performed for the blanks without deviations from the designed geometry. Consequently, the complexity of performance and quality of welded joints in the assembly of the spherical shell depend on the accuracy and stability of the blanks' shape after stamping. Today, the problem of fitting a large number of adjustment operations performed in the manual mode exists in stamping of long blanks.

This problem is related to the significant influence of various factors of the stamping process, including the stamping tool geometry, grade of the petals steel or the stamping route to the final radius of curvature of the obtained petals. Moreover, the cushioning effect is a feature of the stamping of long blanks [11]-[12]. To date, the problem of adjustment (optimization) of stamping technology is mainly solved by performing timeconsuming and costly shop tests. However, the current level of information technology in general, and high-performance computing tools in particular, allow replacing the fullscale experiment by numerical simulation with sufficient accuracy. Together with appropriate modeling, as [13] states, outstanding results can be obtained.

The aim is to define a mutual influence of various factors on each other: the force of stamping and the magnitude of cushioning of deformable sheets, the dimensions and radius of curvature of the working surface of the stamping tool, and the thickness and grade of the steel material, the coordinates, and the sequence of load application. To implement the study goal, the boundary problem was set and a series of numerical experiments allowing to significantly reducing the time-consuming and expensive process of development of new product sizes was performed, including an increase in wall thickness of the sheets and the transition to stronger steel grades. In this article some results of finite-element modeling of the process of consecutive stamping of long blanks for spherical vessels with a volume of $2,000 \mathrm{~m}^{3}$ are presented.

\section{Numerical simulation}

ABAQUS [14] is a software suite for finite element analysis and CAE. It consists of ABAQUS/Explicit and ABAQUS/Standard, which is a general-purpose finite-element code that employs implicit integration scheme, thus it was used here for modeling and analysis. Numerical simulation is based on the existing process of sequential cold stamping of long blanks (tabs) of a spherical vessel on a hydraulic press (Fig. 3). Factory design documents were used as background information about tool and blank geometry. 


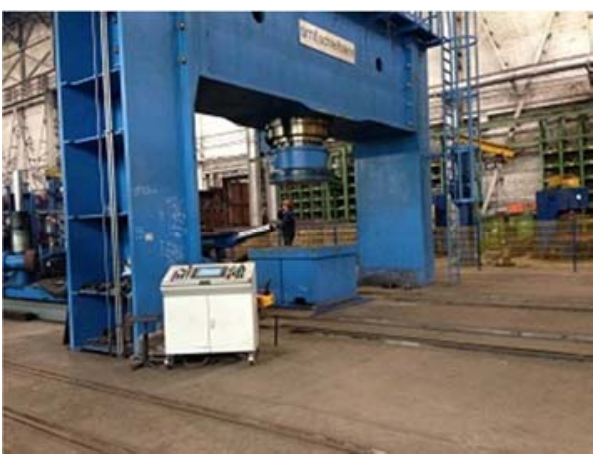

a)

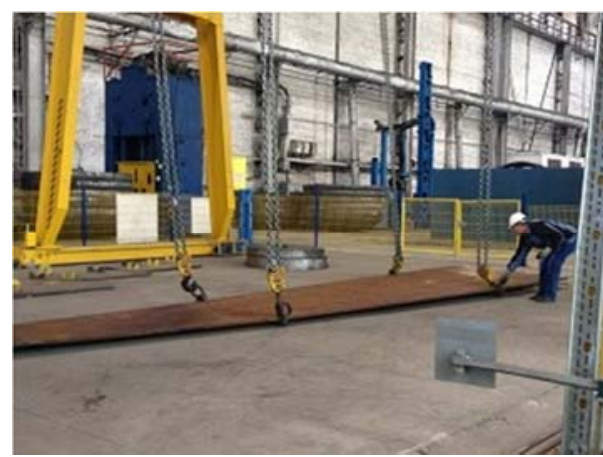

b)

Fig. 3. a) Hydraulic press with the force of $16 \mathrm{MN}$ and b) the blank, (OJSC 'Uralhimmash')

It can be seen in Fig. $4 a$ that in the initial position the set of stamping tools (punches and dies) is set in three series. Only one series of stamping tools is set in the less wide part of the petal. Then, on drawing to the wider part of the blank, the stamping tool slot cannot cover the whole width of the petal, which is a prerequisite to achieve the desired curvature. In this connection, an additional number of stamping tools is set, rotated by a certain angle $8,000 \mathrm{~mm}$ radially (Fig. $4 b$ ). The pitch of the spatial arrangement of stamping tools is maintained. It should be noted that the use of the stamping tool with large geometrical dimensions for the stamping of the widest part of a petal in one series was not considered at this stage of the study. Increasing the size of the punch will inevitably lead to an increase in its weight, which in turn is not desirable in view of limited fly back force of the master cylinder of a hydraulic press.

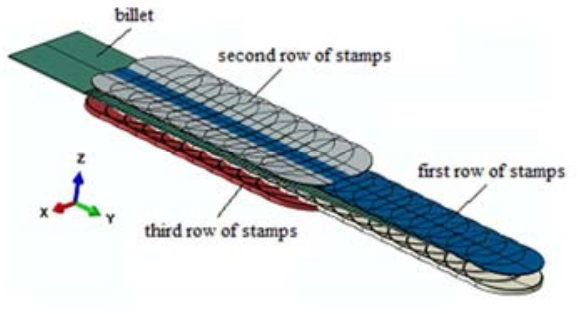

a)

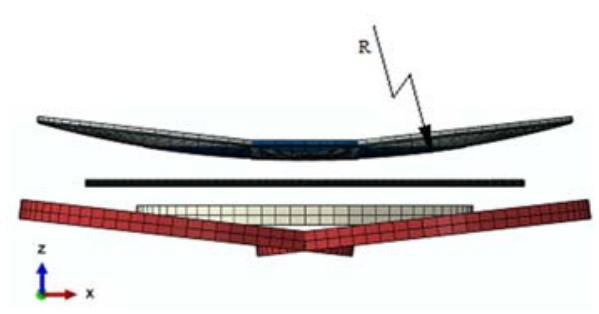

b)

Fig. 4. The geometrical model in CAE system, a) axonometric projection, b) front view

The analysis consists of the following stages: first a rigid punch is displaced in the $\mathrm{z}$-direction (U3) using a displacement boundary condition $(\mathrm{U} 1=\mathrm{U} 2=\mathrm{UR} 1=\mathrm{UR} 2=$ UR3=0). Then a contact interaction between pressing tool and blank is shut off. The analysis is quasi-static. Sequential blank deformation takes place in points in accordance with their numerical order (Fig. 5). A node set lies at surface in the widest section of the blank is fully constrained by enacted boundary condition $(\mathrm{U} 1=\mathrm{U} 2=\mathrm{U} 3=\mathrm{UR} 1=\mathrm{UR} 2=$ 
$\mathrm{UR} 3=0)$. Symmetry boundary conditions $(\mathrm{U} 1=\mathrm{UR} 2=\mathrm{UR} 3=0)$ are applied at the plane lying on the symmetry axis. The stamping tool is absolutely rigid. The contact between the blank and the rigid punch and the rigid die is modeled with a contact pair. The surface-to-surface contact formulation is used. The friction coefficient between all parts is assumed to be 0.2. In Abaqus/Standard elements of type C3D8R, 8-node linear brick, reduced integration with hourglass control, are used. The size of finite element along the petal is $50 \mathrm{~mm}$. Finite element size across the thickness of the workpiece is $5 \mathrm{~mm}$.

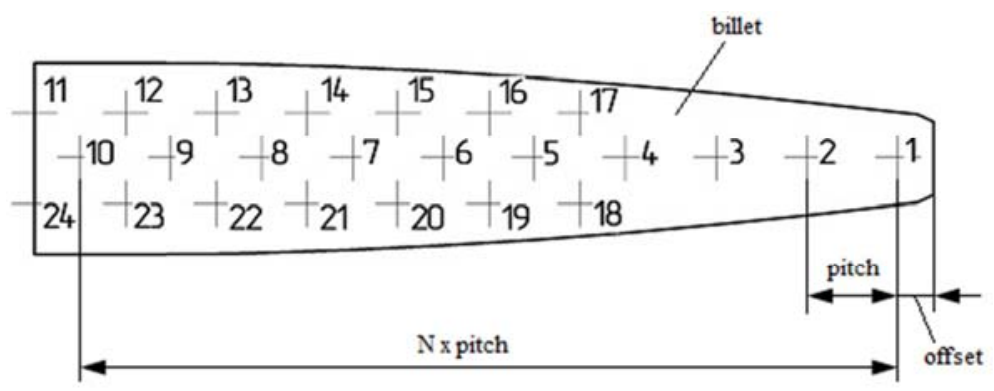

Fig. 5. Stamping process diagram

09G2S low-alloy steel (in accordance with GOST 5520-79) is used as work material for the blank. 09G2S steel has a yield stress of $330 \mathrm{MPa}$, ultimate resistance $480 \mathrm{MPa}$, elongation $21 \%$, and impact resistance at the temperature $-40^{\circ} \mathrm{C}$ not less than $0.35 \mathrm{MJ} / \mathrm{m}^{2}$. For the identification of the elastoplastic model, mechanical axial tension tests were conducted using standard cylindrical test-pieces according to GOST 1497-84. Young's modulus is $205.2 \mathrm{GPa}$, Poisson ratio is 0.275 .

The Abaqus/CAE toolset provides powerful solutions, while the Abaqus Scripting Interface (API) is used to create and modify the components of an Abaqus model, like parts, materials, loads, and steps. A user interface (Fig. 6) was developed and integrated into the Abaqus/CAE system.

The program module allows modeling the geometry of the tool and the blank, and allows selection of materials. The interface of the problem solver is written in Python [15]. The problem solver, the language interpreter and the kernel are working together to generate an incoming file containing model parameters and data of limiting boundary conditions. The problem solver generates an outgoing file of the data base, which is transferred to the Visualization module and processed there to produce graphical and text outputs.

\section{Results and discussion}

Fig. 7 shows the diagrams of equivalent Mises stress and the deformation of the sheet blank at various stages of the stamping process (the stamping tool is not shown).

The extremely inhomogeneous change of stresses is observed on the whole volume of the blank. It is evident that in the front (the narrowest) part of the blank the stress state is significantly different from the rest of the deformable petal both by the stress 
magnitude, and by the pattern of their distribution. Thus, the magnitude of the residual stress in the front part of the blank is approximately $5 \mathrm{MPa}$, while in some areas of the deformable blank the residual stresses reach the value close to the yield strength of the material. The character of stress distribution suggests the need to adjust the magnitude of the applied stamping tool force in this part of the deformable petal. The observed (estimated) permanent deformation of the blank as a result of the influence of the spring factor effect reaches $30 \%$ or more.

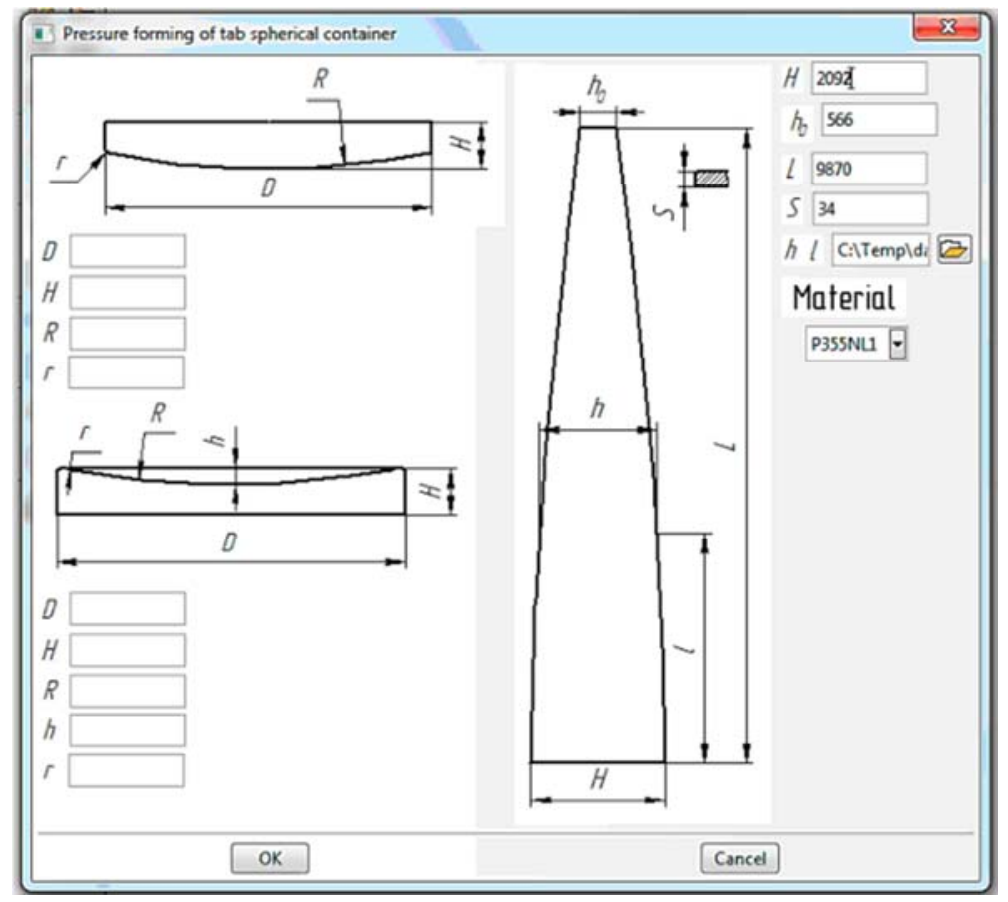

Fig. 6. User interface in Abaqus/CAE system

Fig. 8 displays the distribution of equivalent plastic strains.

It can be seen that understamped areas are present on the blank.

By using this scheme in a cold plastic deformation, the metal mechanical properties (hardness, strength, ductility, toughness, etc.) in the different areas of the blank may significantly vary.

The use of the stamping tool with different curvature of the working surfaces and the adjustment of the stamping effort has not changed the pattern of the plastic deformation areas distribution. Thus, it can be concluded that to ensure a uniform plastic deformation of a deformable petal metal the load application pitch has to be decreased. In the front (narrower) part of the blank the diagrams of the equivalent plastic deformation is inconsistent with the distribution pattern in the body of the sheet. 


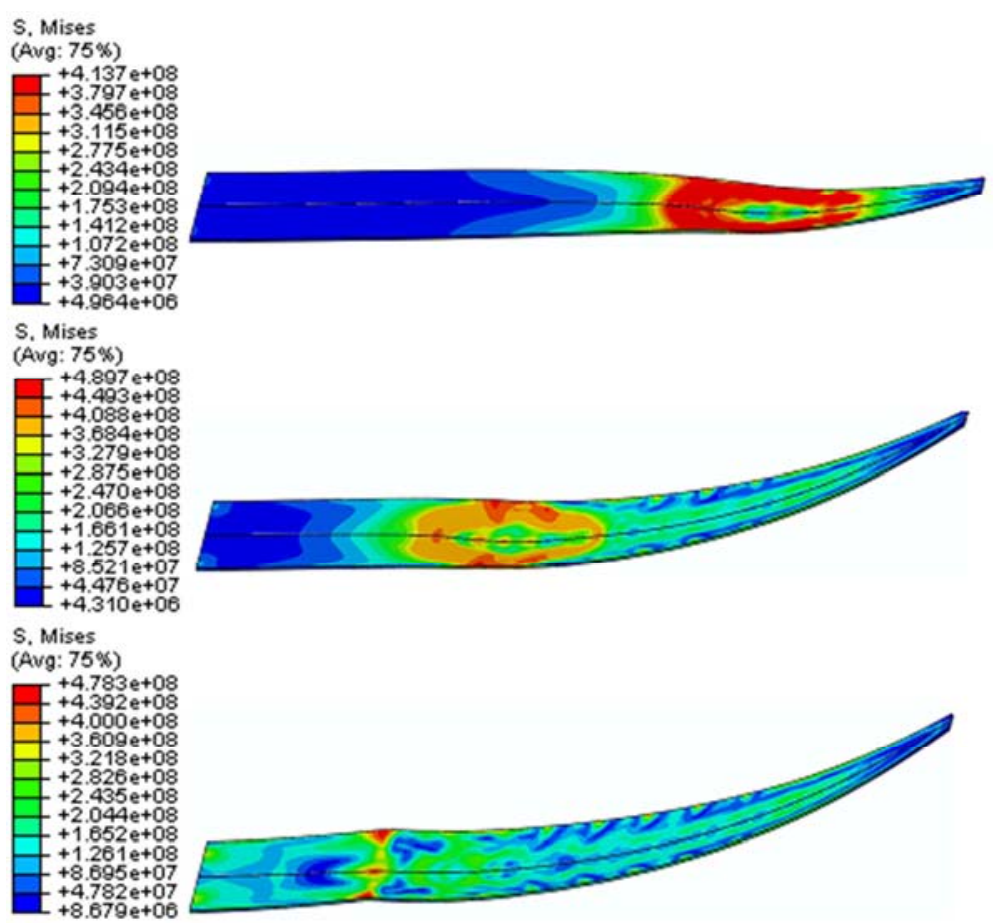

Fig. 7. Distribution of Mises equivalent stress in a blank at different stages of stamping

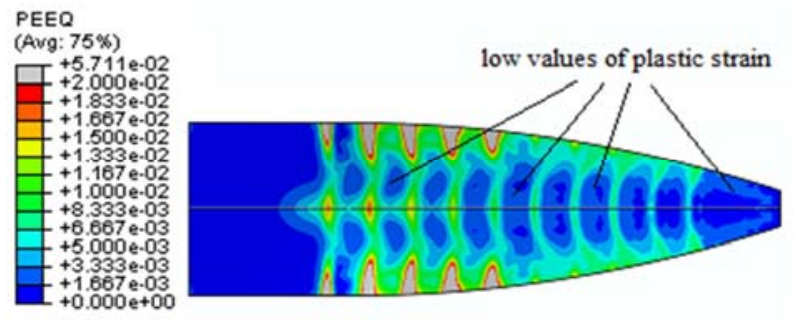

Fig. 8. Distribution of equivalent plastic strain in a blank after stamping

Fig. 9 and Fig. 10 display the calculated values of deformation loads for blanks of different thicknesses $(h,[\mathrm{~mm}])$ with the tag bend radius of $8,000 \mathrm{~mm}$, which is a typical value. Swaging force is presented in percentages of the nominal press force. Apparently, that deformation force varies essentially depending on the place of the load application. It is shown that the distribution of pressure have some dependence. There has been a gradual increase in pressing force from the narrow end to the wide end of the workpiece blank. Fig. 9 shows the values of the stamp efforts for the stamping tool with a radius of curvature of the working surfaces $R_{d}=4,500 \mathrm{~mm}$.

Fig. 10 shows a comparison of the designed values of stamping effort for the $24 \mathrm{~mm}$ thick petal with a radius of curvature of the stamp tools (punch and die) $R_{d}=4,500 \mathrm{~mm}$ 
and 5,400 $\mathrm{mm}$. It can be seen that the increase in the radius of curvature of the stamp tool leads to a significant reduction of the deforming load. The pattern identified leads to the conclusion about the appropriateness of using a stamp with a larger radius of curvature of the working surfaces for stamping blanks with a thicker sheet [16].

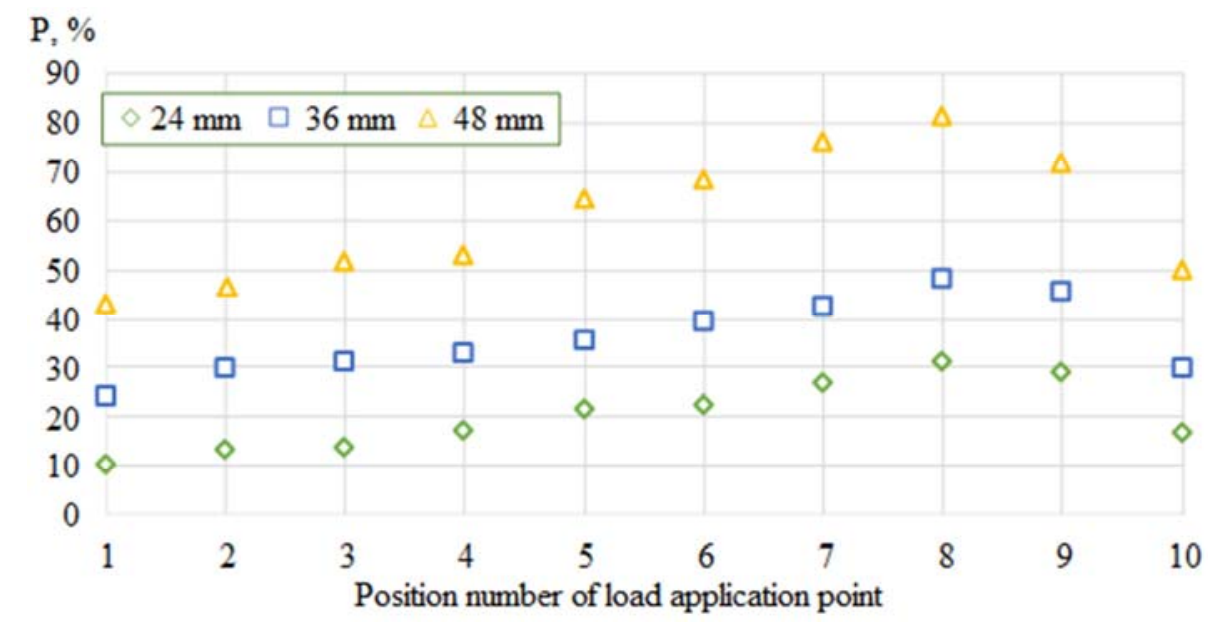

Fig. 9. Stamping force depending on load application point for different blank thicknesses

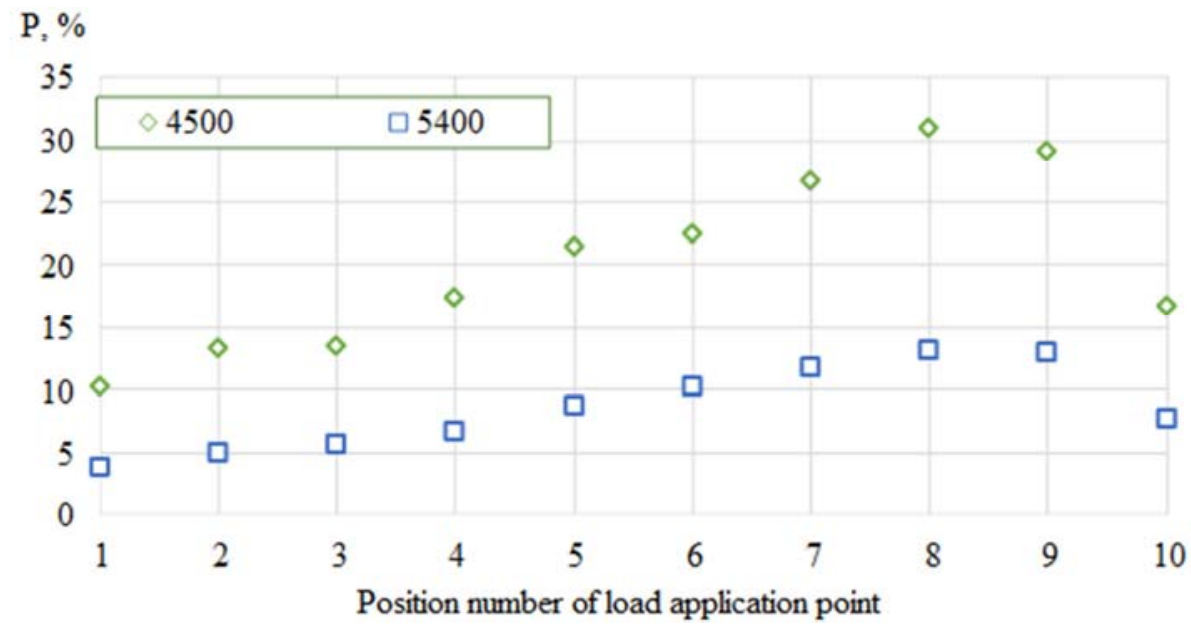

Fig. 10. Stamping force depending on load application point for different tool bend radius

The CAD system was used to measure the blank shape obtained in the process of virtual stamping. By means of additional plane-plotting in different sections of a tag and superposition of sketches of circle of radius $8,000 \mathrm{~mm}$, the deviation of blank shape from theoretical sphere was measured (Fig. 11). 


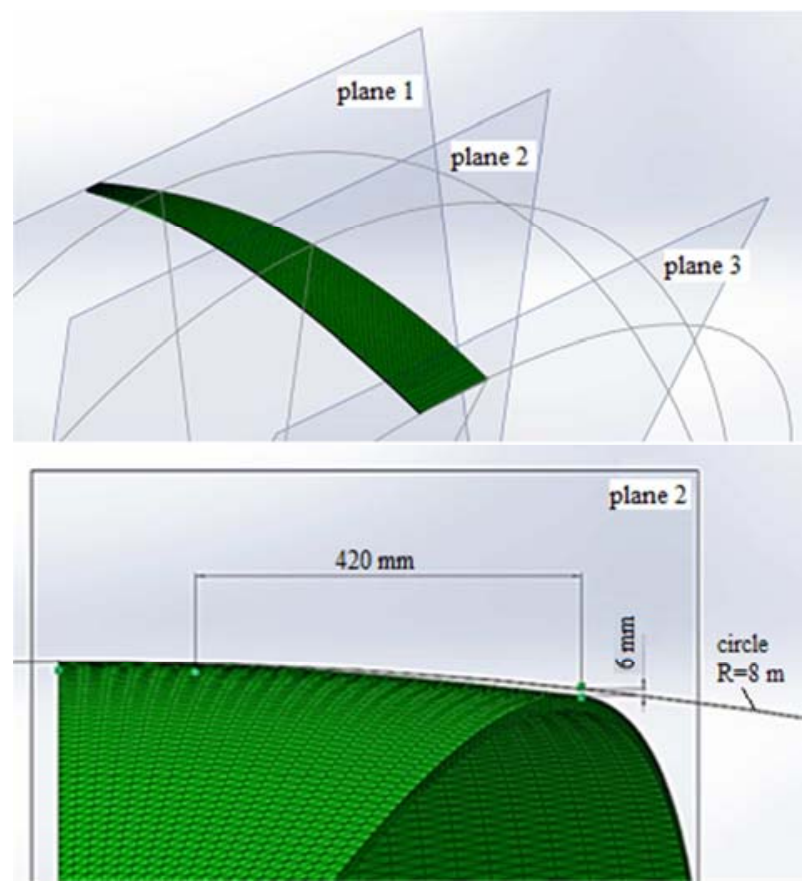

Fig. 11. Deviation shape of the billet after forming the required radius of the sphere

Based on the measurement of the petal shape in the longitudinal and transversal directions, the circuits of deflection of the designed curvature from the reference surface values were drawn. Fig. 12 shows the chart of measurement of $30 \mathrm{~mm}$ thick sheet for the $8,000 \mathrm{~mm}$ radius sphere. The sizes deviations are shown in millimeters and marked in italics on the picture. The dimensions without brackets are for the transverse measurement, the dimensions in parentheses are for the longitudinal measurements. The positive values characterize 're-stamping', i.e. the curvature of the petal surface of less than $8,000 \mathrm{~mm}$. The negative values characterize 'understamping' i.e. the radius of curvature of the sheet surface is greater than $8,000 \mathrm{~mm}$. The largest deviations are observed in the points No. 8 and 9.

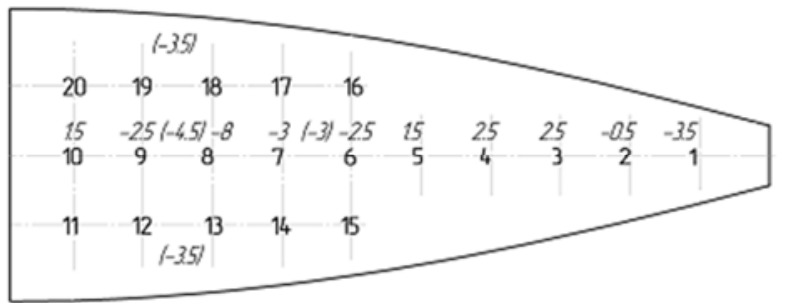

Fig. 12. The chart of the petal sizes deviation in accordance with the route of loads application from the reference curvature of the sphere surface 
The developed finite element model of stamping process has allowed varying the values of technological parameters (pitch and punching force, the radius of curvature of the die and punch, the thickness of the blanks, etc.) without a series of labor-intensive manufacturing tests. The use of numerical simulation does not require the manufacturing of the expensive stamping tool and reduces the time of development of new product sizes.

Additionally, the study of the effect of the stamp working surfaces curvature radius allowed revealing the regularity of the decrease of the stamping force upon the increase of the $R_{d}$ parameter that can be used during the transition to thicker blanks.

\section{Conclusion}

Finite-element simulation of stamping of large-sized bodywork of spherical vessels gave a possibility to determine forces necessary for deformation of a blank with specified radius of curvature with different schemes of load application and variation of main geometric characteristics of working surfaces of the deforming tool. On the basis of the obtained results, recommendations are given for introducing changes in the technology of stamping of tags of spherical vessels with a volume from 600 to 6,600 cubic meters.

In the near future research, it is planned to develop a system for optimal design and production of vessels with different shapes and various sizes.

\section{Acknowledgements}

Authors express thanks to A. F. Kuznetsov, chief metallurgist of OJSC 'Uralhimmash', as well as to Prof. A. G. Zalazinsky for their assistance in conducting numerical experiments and for constructive discussions of the research results.

The work was supported by Act 211 Government of the Russian Federation, contract № 02.A03.21.0006.

\section{References}

[1] Paniti I. CAD API based tool path control for novel incremental sheet forming, Pollack Periodica, Vol. 5, No. 2, 2010, pp. 81-90.

[2] http://en.ekb.ru/projects/upgrade-the-panchevo-refinery/, (last visited 16 September 2016).

[3] Al-Gahtani J. H., Mukhtar F. M. Simplified formulation of stress concentration factors for spherical pressure vessel-cylindrical nozzle juncture, J. Pressure Vessel Technol, Vol. 138, No. 3, 2016, pp. 103-112.

[4] Taghizadeh D. M., Bagheri A., Darijani H. On the hyperelastic pressurized thick-walled spherical shells and cylindrical tubes using the analytical closed-form solutions, Int. J. Appl. Mechanics, Vol. 7, No. 2, 2015, pp 1015-1041.

[5] Radovan P., Miroslav Ž., Marko T., Radovan S. Analytical, numerical and experimental stress assessment of the spherical tank with large volume, Technical Gazette, Vol. 22, No. 5, 2015, pp. 1135-1140. 
[6] Wang T., Li J., Chen Z., Wu L., Cao Z., Li T. Three-dimensional analysis and design of petal-like mould for continuous casting of steels, Journal Ironmaking \& Steelmaking, Vol. 40, No. 1, 2013, pp. 25-31. I

[7] Yuan S. J., Zhang W. W., Teng B. G. Research on hydro-forming of combined ellipsoidal shells with two axis length ratios, J. of Materials Proc. Techn, Vol. 219, 2015, pp. 124-132.

[8] Cai Z. Y., Wang S. H., Xu X. D., Li M. Z. Numerical simulation for the multi-point stretch forming process of sheet metal, Journal of Materials Processing Technology, Vol. 209, 2009, pp. 396-407.

[9] Ju L., Altan T. Forming Al alloys at elevated temperatures, ( Part I. -II) Stamping Journal, No. 676-3 May/June, No. 676-4, July/Augst, 2015.

[10] Radnay L., Iványi M. Strengthening of steel structures using the stiffening effect of cladding, Pollack Periodica, 2012, Vol. 7, No. 2, pp. 47-58.

[11] Yu T. X., Johnson W., Stronge W. J. Stamping rectangular plates into doubly-curved dies, Proceedings of the Institution of Mechanical Engineers, Part C, Journal of Mechanical Engineering Science, Vol. 198, No. 8, 1984, pp. 109-125.

[12] Yu T. X., Johnson W., Stronge W. J. Stamping and spring-back of circular plates in hemispherical dies, International Journal of Mechanical Science, Vol. 26, 1984, pp. 131-148.

[13] Merin M., Avinashe K. K. Internal model control design for nonlinear spherical tank level, International Journal of Engineering Technology Science and Research, Vol. 2, No. 8, 2015, pp. 12-18.

[14] Hibbitt Karlsson \& Sorensen Inc, ABAQUS Theory Manual, Version 6.12, 2006.

[15] GOST 5520-79, Russian Standard, Russian Standards Publisher, UDK669.14 - 413.62, 213.6:006.354, 01.01, 1980, pp. 1-17.

[16] https://www.codecademy.com/learn/python (Python, Cod-academy, 2015) (last visited 16 September 2016)

[17] Tisza M, Lukács Zs. Formability investigations of high strength dual-phase steels, Acta Metallurgica Sinica, English Letters, Vol. 28, No. 12, 2015, pp. 1471-1481. 